\title{
MULTICULTURALISMO E PROTEÇÃO JURÍDICO-INDUSTRIAL DA SABEDORIA DETIDA PELAS POPULAÇÕES TRADICIONAIS NA AMAZÔNIA.
}

\author{
Daniela Gonçalves de Carvalho ${ }^{1}$
}

\section{Resumo:}

O trabalho a seguir apresenta um estudo sobre o Multiculturalismo, tomando como marco teórico a obra de Kymlicka acerca do tema da multipluralidade social e do devido reconhecimento de populações tradicionais. O recorte é feito a partir da proteção jurídica das populações indígenas da Amazônia, levando em conta a especial riqueza natural da região. Examinaremos, primeiramente, o aparato institucional de proteção, e, em seguida os instrumentos de proteção da propriedade natural e intelectual da sabedoria indígena, expondo a fragilidade do ordenamento brasileiro nesse ponto tão sensível.

Palavras-chave: Multiculturalismo, Povos indígenas, Recursos naturais, Proteção jurídica, Patentes.

\section{MULTICULTURALISM AND LEGAL-INDUSTRIAL PROTECTION OF WISDOM HELD BY TRADITIONAL POPULATIONS IN THE AMAZON.}

\begin{abstract}
:
The following work presents a study on Multiculturalism, taking as theoretical framework the work of Kymlicka on the theme of social multiplurality and the due recognition of traditional populations. The cut is made from the legal protection of the indigenous populations of the Amazon, taking into account the special natural wealth of the region. We will first examine the institutional apparatus of protection, and then the instruments of protection of the natural and intellectual property of indigenous wisdom, exposing the fragility of the Brazilian order in this sensitive point.
\end{abstract}

Keywords: Multiculturalism, Indian people, Natural resources, Legal protection, Patents.

\section{INTRODUÇÃO}

A riqueza que abriga o Bioma dentro da floresta amazônica é imensurável. Veremos que urge despertar a comunidade jurídica para o aparelhamento protetivo da biodiversidade e do conhecimento tradicional de seus povos. Tal abundância de recursos e detenção sobre os conhecimentos naturais é a razão de grandes indústrias de todo o mundo, e até mesmo de

\footnotetext{
${ }^{1}$ Mestranda no PPGD - UNIRIO - Mestrado em Direito e Políticas Públicas da Universidade Federal do Estado do Rio de Janeiro. Procuradora Federal.
} 
Estados estrangeiros, terem imenso interesse no patrimônio biogenético e cultural da Amazônia. Aí reside a relevância de um estudo que demonstre os principais instrumentos e instituições jurídicas de proteção de sua flora, fauna e de seus povos originários. Becker (BECKER, 2006, p.357) muito bem define tamanha grandeza:

\footnotetext{
É fácil perceber a importância da riqueza in situ da Amazônia. Correspondendo a 1/20 da superfície da Terra, e a 2/5 da América do Sul, a Amazônia Sul-Americana contém 1/5 da disponibilidade mundial de água doce, 1/3 das reservas mundiais de florestas latifoliadas e somente 3,5 milésimos da população mundial.
}

Com o intuito de auxiliar o leitor no conhecimento, e possível aplicação dos meios de proteção, será realizada uma interpelação dos substratos jurídicos de propriedade intelectual discutidos na legislação pátria. Veremos que muito além de ser uma fonte inesgotável de matéria-prima para medicamentos, o que em muito desperta o interesse da indústria farmacêutica, o patrimônio biológico pode servir também para abastecer a indústria alimentícia, de energia e, até, de cosméticos. Levaremos em conta, especialmente, o conhecimento secular das populações indígenas e comunidades tradicionais como objeto merecedor de proteção jurídica.

A população indígena, que já foi maioria absoluta da população brasileira, está incrivelmente reduzida. Segundo dados fornecidos pela FUNAI, em 1500 havia 3.000.000 de índios no Brasil, em 2010 não chegavam a 1.000.000, eram cerca de 800.000 tão somente (FUNAI, 2015). Nossas raízes, o quem somos, decorre direta, ou, indiretamente desses povos. Por isso, e não só por isso, de suma importância, manter vivos seus costumes, interagir com eles e, acima de tudo, preservá-los, mantê-los vivos, pois eles não representam a cultura majoritária, suas leis não nos são impostas, mas, como minoria que são, dependem da proteção do Ordenamento para se manterem.

Dentro desse cenário, a Procuradoria Geral Federal, órgão vinculado à AGU, através da Procuradoria Especializada junto à FUNAI exerce um papel fundamental e pouco divulgado: através do aparato da FUNAI, com antropólogos e especialistas, oferece-se proteção jurídica de qualidade e com respeito à individualidade das mais diversas etnias.

Neste trabalho, propomo-nos a despertar no leitor a reflexão acerca do Reconhecimento do diferente, bem como a apresentar um pouco mais das especificidades que 
permeiam este ramo tão plural dos direitos fundamentais. Além de examinar a questão das patentes decorrentes do conhecimento tradicional e defender uma proteção mais efetiva.

\section{1- O reconhecimento e multiculturalismo como passos essenciais à proteção.}

A temática do reconhecimento não é novidade. Ao contrário, já podia ser encontrada na obra de Hegel (FRASER e HONNETH, 1995), na qual este autor destaca o caráter dialógico da construção da identidade. A percepção do outro sobre cada ser reflete diretamente na autoestima do sujeito e na sua construção de identidade, tanto sob a ótica individual, quanto sob a ótica do coletivo.

Para iniciar, vamos deixar bem claro o que o reconhecimento não é. Ele não consiste na mera cognição superficial do outro. Está atrelado ao conceito de empatia, de enxergar o outro enquanto unidade complexa e única, respeitando quem ele é, de onde veio, e o que traz na sua bagagem.

No tocante à ausência do reconhecimento, Daniel Sarmento (SARMENTO, 2016), ensina que a sua falta ou o seu uso deturpado leva a posturas desrespeitosas, com consequente diminuição do sujeito, o que importa em degradação e comprometimento da sua possibilidade de tomar parte, como um igual, nas relações sociais.

Logo, grupos que desenvolvam comportamentos díspares do dominante, seja em razão de sua origem, etnia, orientação sexual, buscam o reconhecimento das próprias tradições e costumes, do seu modo próprio de ser, unindo-se como modo de sobrevivência. É o caso das comunidades tradicionais, como as etnias indígenas amazônicas.

Neste ponto sensível deve ser cirúrgica a atuação jurídica, e é de extrema importância que o Direito incida a fim de não admitir a diminuição subjetiva de determinados grupos. A solução encontrada por Nancy Fraser (FRASER e HONNETH, 1995) foi a paridade na participação. Pelo critério de participação sugerido pela autora, a distribuição de recursos materiais deve assegurar aos participantes independência e voz. Ela também defende que os padrões institucionalizados de valor cultural devem expressar igual respeito a todos os participantes da sociedade, garantindo-lhes paridade de armas para atingir a estima social, o que se aplica, por óbvio, aos povos tradicionais.

Proteger juridicamente o reconhecimento consiste em tarefa árdua, que se impõe tanto aos Legisladores, quanto aos operadores do direito, a exigir sensibilidade e estudos 
multidisciplinares. Afinal, sem pretensões de resumir este tema tão profundo e complexo, podemos afirmar que o direito ao reconhecimento tem previsão na ordem jurídica brasileira?

Não só tem, como tem status de direito fundamental. Apesar de não haver previsão expressa, "O princípio da dignidade da pessoa humana tem no reconhecimento intersubjetivo uma dimensão muito importante (PIOVESAN, 2008).” Já Sarmento, o enxerga como sendo subprincípio do princípio da igualdade (SARMENTO, 2015). Assim, seja na igualdade $\left(\mathrm{CRFB}\right.$, art. $\left.5^{\circ}\right)$, na solidariedade ou na dignidade da pessoa humana (CRFB, art. $\left.1^{\circ}, \mathrm{III}\right), \mathrm{o}$ reconhecimento está presente, ainda que de forma implícita, na nossa Constituição. Desconhece-se literatura que defenda o oposto.

Superada a questão do reconhecimento multicultural, e sua proteção na Constituição, passemos à análise do multiculturalismo em si.

\section{2- O Multiculturalismo e os índios do Brasil.}

O multiculturalismo pode ser compreendido como o complexo multidisciplinar de políticas públicas, estudos acadêmicos e teorias acadêmicas que focam no conjunto de povos de origens e culturas próprias, dentro de uma sociedade plural. O contato entre as populações originárias e as pessoas dominantes pode ser pacífico ou não, a depender da localidade e das etnias envolvidas. Seu conceito é inserido dentro de um quadro de globalização, com contato intenso entre tradições e costumes muito diferentes entre si, o que tende a gerar fortes impactos.

Ao abordar o Multiculturalismo, é imperioso explicitar os estudos do filósofo canadense Charles Taylor. Taylor (TAYLOR, 1998) questionava a pretensão de Estados universalistas, e propunha a construção de uma sociedade democrática, multicultural, alicerçada no diálogo entre comunidades diversas ou grupos étnicos, o que seria a base de uma sociedade multicultural. Fácil perceber que seus estudos são bem próximos à nossa temática.

O principal autor considerado neste trabalho é o canadense liberal Will Kymlicka. Kymlicka é um filósofo político contemporâneo conhecido por abordar o multiculturalismo e a ética animal. Especificando o trabalho deste autor, Adinan Silveira (SILVEIRA, 2014) ensina que: 
Kymlicka percebeu que nas sociedades liberais modernas, muitas minorias sofrem injustiças relativas ao bem de pertença cultural, cuja correção requer a justificação e o reconhecimento de direitos específicos, pois os direitos da minoria - ao contrário da perspectiva liberal clássica - não são privilégios injustos ou formas detestáveis de discriminação, mas compensações por vantagens injustas. Por isso, pode-se considerá-los consistentes com a justiça e exigidas por ela.

As minorias, dentro da sociedade multicultural, podem ser definidas como grupos vulneráveis em razão de seus traços culturais marcantemente distintos do grupo dominante, além de serem menores quantitativamente. O risco que os assola é o de esmagamento, o de serem engolidos pela onda cultural ocidental norte-americana, a qual viria a emergir após a Guerra Fria. Seu maior desafio atualmente é a sobrevivência.

Dentro dessa posição de não-dominância, há grupos de minorias religiosas, étnicas e linguísticas. Em nosso estudo, vamos nos restringir às minorias étnicas, mais precisamente as indígenas e a sua proteção jurídica dentro do território nacional.

Nesse espectro dos direitos fundamentais, dentro de um mundo plural, não é lícito ou legítimo considerar qualquer cultura ou tradição inferior, tampouco superior ou exigir a sua submissão às demais.

Apesar de serem, axiologicamente, considerados minorias, os tribais estão presentes em todas as regiões do Brasil. De acordo com dados da FUNAI (FUNAI, 2015), a região Norte é a que concentra a maior população, com 305.873 mil indivíduos. Ademais, a etnia Tikuna, Do Estado do Amazonas, em números absolutos, foi o que apresentou o maior número de falantes e consequentemente a maior população. Em segundo lugar, em número de indígenas, ficou o povo Guarani Kaiowá do Mato Grosso do Sul e em terceiro lugar os Kaingang da região Sul do Brasil.

Nosso DNA miscigenado tem muito mais desses povos do que estatísticas podem obter: no caldeirão cultural no qual estamos imersos vários dos nossos costumes não são europeus, mas, são indígenas. O banho diário, o uso da mandioca como alimento, o pescado fresco na mesa, dentre tantos outros.

Conhecidos hábitos nossos, nada disso assusta. Contudo, notícias recentes da mídia noticiam o horror envolvendo índios: mãos decepadas, torturas nas mãos de capangas de fazendeiros na briga por terras, o esmagamento literal do diferente (CAMPELO, 2017). Como se dá a proteção jurídica dessas minorias, especificamente? 


\section{3- A proteção jurídica da sabedoria multicultural indígena acerca dos recursos naturais no Brasil, especialmente na Amazônia.}

O multiculturalismo, abrange a proteção do sociocultural, o qual ganha relevante proteção da Constituição de 1988. Para ilustrar, tomemos o artigo 215, o qual assegura a todos o direito de pleno exercício das práticas culturais e o acesso às fontes de cultura nacional com o apoio, incentivo e garantia do Estado.

Constituem patrimônio cultural brasileiro os bens de natureza material e imaterial, tomados individualmente ou em conjunto, portadores de referência à identidade, à ação, à memória dos diferentes grupos formadores da sociedade brasileira, nos termos do artigo 216 da Carta Magna. Consideram-se como bens materiais e imateriais as formas de expressão, os modos de criar, fazer e viver, as obras e espaços destinados às manifestações artísticoculturais e originárias.

Destas normas constitucionais mencionadas, nasce no Estado de Direito Brasileiro refundado com a Constituição de 1988 (STEFANELLO e DANTAS, 2007):

a proteção aos conhecimentos construídos e praticados pelas comunidades indígenas e tradicionais em relação à biodiversidade, em especial, como foco do presente estudo, a socio biodiversidade amazônica, que compreende as centenas de etnias indígenas que convivem em harmonia com a natureza, cultuando seus rituais e preservando seus costumes e saberes acerca das propriedades medicinais contidas no rico meio-ambiente amazônico.

Está concentrado no espaço da Amazônia, a maior diversidade de etnias indígenas (STEFANELLO e DANTAS, 2007). No Brasil, os povos indígenas já faziam uso de bens materiais bem antes da chegada de portugueses, espanhóis e franceses (BENSUSAN, 2005), contudo, eram considerados povos "inferiores, selvagens", por isso, toda a sua sabedoria foi ignorada durante um bom tempo. Porém, com a exploração crescente dos recursos naturais amazônicos, constatou-se que eram os indígenas quem detinham maior conhecimento sobre os produtos extraídos dos recursos naturas da região, o que gerou imenso interesse industrial sobre eles, demandando, cada vez mais e mais incisiva proteção. 
Um caso de biopirataria de grande repercussão fez com que o governo editasse uma medida provisória de caráter protetivo (http://www.comciencia.br/dossies-172/reportagens/amazonia/box/gama.htm - acesso em 17.10.2019):

Em função de um contrato mal feito entre a Bioamazônia (uma organização social criada com o incentivo do governo) e a multinacional suíça da área farmacêutica e biotecnológica, Novartis, destinado a fazer bioprospecção de plantas de interesse comercial da região amazônica, o governo brasileiro baixou uma medida provisória (MPV nº 2.052, 29/6/2000) proibindo (até sua regulamentação em 30/12/2000) a saída de material genético do Brasil para outros Estados do Brasil e Exterior.

A medida continha inúmeros aspectos positivos, dentre os quais podemos destacar a proteção dos direitos das comunidades indígenas, a regulamentação da repartição dos benefícios advindos do uso do patrimônio genético com o intuito de pôr à cabo a biopirataria. Ainda assim, a legislação restou duramente criticada sob a alegação de inviabilizar a exploração de recursos naturais amazônicos. (TÁVORA e outros, 2015).

Após inúmeras discussões na arena de debates do Congresso Nacional, em 2014 foi apresentado um projeto de lei que cuidaria, enfim, da matéria veiculada pela MP 2052, o qual veio a se tornar a Lei $\mathrm{n}^{\mathrm{o}} 13.123$, de 2015 , que será abordada com maior profundidade mais à frente.

\section{1 - Da proteção institucional dos povos indígenas.}

No plano internacional, merece destaque a Declaração Universal dos Direitos dos Povos Indígenas, do ano de 2007. A Declaração foi aprovada pelas Nações Unidas, após estudos que tiveram início na década de 1980 e que comprovaram a violação de direitos a que estes povos estiverem historicamente submetidos. A Declaração referida se baseia no princípio de que os povos e indivíduos indígenas são iguais e livres aos demais povos, além de adotar como princípio a não assimilação forçada.

Temos também a Convenção sobre Diversidade Biológica (CDB), estabelecida em 1992, fruto do encontro internacional conhecido como ECO 92, na cidade do Rio de Janeiro, da qual o Brasil é signatário e constitui um dos instrumentos internacionais principais de proteção ao meio ambiente. Uma das mais relevantes contribuições deste Tratado 
Internacional consiste no reconhecimento da soberania dos países sobre seus recursos biológicos, incluídas as populações tradicionais.

No âmbito nacional, temos uma manta protetora dos direitos indígenas na nossa Constituição. No Capítulo VIII, artigos 231 e 232, temos uma dedicação constitucional especial aos povos indígenas. Além dos direitos à educação e reconhecimento de suas tradições enquanto cultura pelos artigos 210 e 215 da Carta de Direitos. Percebe-se, a partir da promulgação da CRFB de 1988, uma mudança de paradigmas, de vontade do constituinte, através da qual o Estado deixa de ser tutor da pessoa do índio e passa a ser tutor dos direitos da pessoa índia.

O artigo 129, III da Constituição traz o Ministério Público como defensor dos direitos e interesses coletivos e difusos, através dos instrumentos que possui, principalmente a ação civil pública. Assim, como primeiro guardião dos direitos do índio aqui mencionados, destacamos o Ministério Público e a independência de atuação que lhe trouxe a Carta Magna.

Em seguida, temos a FUNAI, Fundação Nacional do índio, criada em 1967. A FUNAI tem papel central na promoção do acesso aos índios a políticas públicas especificamente a eles direcionadas e a sua proteção, além de funcionar como ponte integrativa entre culturas díspares por diversas vezes.

A representação judicial, e consultoria extrajudicial da FUNAI, fica a cargo da Procuradoria Geral Federal, órgão vinculado à Advocacia Geral da União, função constitucional essencial à Justiça, portanto. A Lei número 9.028/95, em seu artigo 11, parágrafo $6^{\circ}$ destaca o papel da Procuradoria Federal na defesa dos índios e da FUNAI. O Decreto 7778 de 2012, reforça em seu artigo 14, III competir a este órgão a defesa dos interesses e direitos individuais e coletivos indígenas.

Ao procurador federal cabe o zelo por interesses individuais ou coletivos dos povos indígenas. Há casos em que o choque cultural se torna denso e demanda uma atuação, de fato, especializada. São verdadeiros hard cases.

Há questões coletivas explícitas, como a Demarcação de Terras, e os conflitos agrários que, tradicional e infelizmente, deixam os índios machucados em sua existência. O mais recente ocorreu no Estado do Maranhão, no qual os índios relataram tortura pelos Fazendeiros e um dos índios chegou a ter as mãos decepadas (THE INTERCEPT, 2019). A inferioridade armamentista e a vulnerabilidade do povo tribal fazem dele alvo fácil, no que demanda proteção incisiva e real do Estado. Lembrando que o direito à terra, especificamente para o 
índio, tem status de direito fundamental, consoante afirmado pelo Ministro Ayres Brito ao julgar o caso Raposa Serra do Sol (Pet. 3388/RR).

No dia 05 de maio de 2017, durante a sessão do Conselho de Direitos Humanos da ONU, o Brasil foi questionado e pressionado publicamente sobre a proteção dos Direitos Humanos de populações indígenas. O saldo de feridos no episódio no Maranhão acima descrito passa de dez. Na mesma semana teve início a Comissão Parlamentar de Inquérito da FUNAI-INCRA, duramente criticada por ter sido iniciada justamente pela bancada ruralista do Congresso. Os representantes eleitos do grande empresariado rural militam aberta e politicamente pela restrição do direito dos povos indígenas à terra (ONU, 2017).

Por fim, até em questões criminais há defesa do índio pela Procuradoria Federal, a qual costuma utilizar, como aplicação prática do multiculturalismo, o laudo antropológico como instrumento de defesa penal do índio. Lembrando que, consoante o teor do Enunciado 140 do Superior Tribunal de Justiça, compete à Justiça Comum Estadual processar e julgar crime em que o indígena figure como autor ou vítima. Ainda nesses casos, nada impede a defesa técnica do indígena por Procurador Federal.

Não há cenário ideal. Ao revés, os casos concretos narrados neste paper como exemplos do nosso objeto de estudo revelam abusos de pessoas que integram a cultura dominante sobre o vulnerável, de forma individual e coletiva. Entendemos que os órgãos jurídicos de proteção dos povos indígenas possuem legitimidade para pleitear em juízo os direitos decorrentes da utilização de conhecimento tradicional de populações originárias sobre o modo de utilizar bens materiais ou imateriais amazônicos.

\section{2 - Da proteção jurídica específica acerca da sabedoria amazônica de potencial} interesse industrial.

Após termos visto como se estrutura no Ordenamento, a proteção jurídica dos povos tradicionais no Brasil, vamos especificar alguns instrumentos legais que funcionam como arcabouço de proteção da sabedoria milenar detida sobre os recursos naturais da Amazônia.

Como dito no tópico 2, o Estado multicultural em que vivemos, resulta numa visibilidade inevitável das populações amazônicas. Deste modo, o que já foi visto como rudimentar e inferior, hoje, é reconhecido como uma inesgotável fonte de recursos naturais de interesses industriais com capacidade de gerar enormes lucros. Segundo Stefanello e Dantas: 
O que antes era ignorado, por ser diferente, irracional e folclórico, passou a ser visto como uma fonte inesgotável de novas riquezas, justamente em razão da sua diversidade. Percebeu-se, então, que as populações tradicionais e indígenas, além de serem importantes para a preservação da biodiversidade e de facilitarem a prospecção de novos produtos que vão para o bilionário mercado da biotecnologia, também têm sido valorizadas pelas empresas por agregarem valor aos novos produtos "inventados", conferindo-lhes uma imagem mais natural, saudável, social e ambientalmente responsável.(STEFANELLO e DANTAS, 2007, p. 4106).

A região da Amazônia é muito disputada, em razão de todo o seu potencial biomaterial, pois, seus territórios abrigam uma das maiores reservas hídricas, de fauna e flora do mundo. Isso alimenta as discussões sobre como fazer uso de seus recursos de maneira sustentável, beneficiando a humanidade com toda a sua riqueza, de maneira a não degradar e a preservar seus povos e tradições. De acordo com Amin (AMIN, 2015, versão digital - sem paginação): "Portanto a Amazônia confronta-se, hoje, com cenários internacionais bastante conflitantes nos quais prevalece o paradigma do desenvolvimento sustentável".

A fim de defender a proteção dos conhecimentos através de patentes, vamos destrinchar seu conceito. Considera-se patente a formalização, expedida pelo Instituto Nacional de Propriedade Industrial, INPI, pela qual se conferem e se reconhecem direitos de propriedade e uso exclusivo para uma invenção descrita amplamente.

De acordo com Lei da Propriedade Industrial, $n^{\circ}$. 9.279, de 1996, cuida-se de uma prerrogativa conferida pelo Estado aos inventores, que, a partir do registro da patente, se tornam detentores do direito de invenção de produtos e processos de fabricação, ou aperfeiçoamento de algum já existente. A partir de uma análise do conceito legal de patente, urge reconstruir a natureza e o conteúdo da lei de modo a incorporar, no processo de conferência de patentes o registro de recursos biológicos pelo INPI, o que denotaria respeito e teria o condão de conferir proteção mais efetiva ao conhecimento cultural e tradicional como uma ferramenta de desenvolvimento. O que foi feito, de certa forma, pela Lei 13.123 de 2015 .

A doutrina aponta como a tecnologia científica é monopolizada pelo mercado produtivo na atualidade, colocando o lucro acima de outros direitos, inclusive de direitos originários de autoria (FRITZ, 2004). Leciona-se que a ciência tem como fulcro fomentar a tecnologia, a qual obedece a um sistema de produção com o intuito de atender às demandas do mercado. O grande problema é que no caso da Amazônia, muitas pesquisas dadas como 
inéditas, já eram utilizadas há séculos da maneira cientificamente adequada por populações indígenas.

Isso vai de encontro ao conceito jurídico de novidade, que requer um senso de inovação que não faça parte do estado da técnica. De acordo com os ensinamentos de sociedade multicultural acima vistos, o conhecimento tradicional associado deve ser compreendido como parte descoberta merecedora de proteção e registro no INPI. De acordo com Feres e Moreira:

\footnotetext{
Em virtude disso, é racional considerar que o conhecimento tradicional é parte do estado da arte. É verdade que cientistas irão melhorar medicamentos, cosméticos, etc., recorrendo às experiências advindas do conhecimento tradicional. Todavia, tal processo de busca deve ser controlado de forma a desrespeitar e, até mesmo, furtar características culturais pertencentes à biodiversidade. Assim sendo, o conhecimento tradicional deve ser considerado como parte do estado da técnica, o que demandará de multinacionais farmacêuticas e cientistas um esforço real para provar a novidade de seus produtos e sua utilidade para além de como são localmente processados os recursos genéticos e as substâncias naturais encontrados em comunidades tradicionais. (FERES E MOREIRA, 2014, P. 26).
}

A Lei $\mathrm{n}^{\mathrm{o}} 13.123$ de 2015, mencionada no fim do tópico 3.1, revogou a Medida Provisória $\mathrm{n}^{\mathrm{o}} 2.186-16$, de 23 de agosto de 2001, consistindo no novo marco legal de acesso ao patrimônio genético, a proteção e o acesso ao conhecimento tradicional associado e sobre a repartição de benefícios para conservação e uso sustentável da biodiversidade.

Os artigos 8, 9 e 10 da legislação de 2015 versam sobre o reconhecimento e da proteção dos direitos de povos indígenas, de comunidades tradicionais ou de agricultores tradicionais sobre o conhecimento tradicional associado ao patrimônio genético, dispondo ainda sobre o acesso a esse conhecimento e prevendo a obrigatoriedade da repartição de benefícios pela respectiva exploração econômica. O conhecimento tradicional passa a ser identificado em publicações de cunho científico, seu registro em cadastros ou em bancos de dados, ou sua presença em inventários culturais. A legislação reconhece o caráter coletivo da sabedoria indígena, ou conhecimento tradicional, como denominado na legislação, ainda que somente uma pessoa da comunidade o detenha.

A lei número 13.123/2015 vincula a exploração do conhecimento tradicional, que pode ser materializada em receitas de remédios com recursos naturais, e.g., ao consentimento informado de seus detentores, ressalvado o conhecimento tradicional de origem não 
identificada em razão da enorme difusão popular, como por exemplo a noção de que chá de erva cidreira alivia inchaços e não é possível determinar quem trouxe este conhecimento em primeiro lugar. Este consentimento prévio informado envolve a assinatura de termo, registro audiovisual, parecer da FUNAI ou adesão em formas que a própria comunidade estabeleça.

O diploma legal assegura aos possuidores de conhecimento tradicional associado ao patrimônio genético os direitos de ter reconhecida sua contribuição; indicação da origem do acesso a esse conhecimento; perceber benefícios pela exploração econômica do seu conhecimento; participar do processo de tomada de decisão sobre o acesso ao seu conhecimento e sobre a repartição de benefícios decorrentes; usar, vender, conservar, manejar, guardar, produzir, trocar, desenvolver, melhorar livremente produtos e material reprodutivo que contenham patrimônio genético ou conhecimento tradicional associado (art. 10, lei 13.123/2015).

Foi elaborado um estudo durante a $8^{\mathrm{a}}$ Conferência das Partes (COP-8) da Convenção sobre Diversidade Biológica (CDB) e apresentado também no Conselho de Gestão do Patrimônio Genético (CGEN) (MINISTÉRIO DO MEIO AMBIENTE, acesso em 2019) com o fim de implementar os comandos da nova lei. A intenção é que seja possível a criação de um regime eficiente de controle de patentes relacionadas ao patrimônio genético e ao conhecimento tradicional associado, para que a legislação não se torne "letra morta". Isso para que haja meios mais eficazes de rastrear se o acesso foi feito legalmente e se houve a devida repartição de benefícios através de compensação financeira. Esses procedimentos já constam do ordenamento desde a primeira legislação de recursos genéticos, e urge intensificar o seu uso. Cuida-se do certificado de procedência legal para pedidos de patentes que envolvam acesso a recursos genéticos ou conhecimentos tradicionais.

Desde 27 de fevereiro de 2018, tem sido emitida, de maneira automática uma exigência formal nos pedidos de registro de patentes formulados junto ao INPI obrigando aos requerentes comprovarem o cadastro ou autorização de acesso ao Patrimônio Genético Nacional ou do Conhecimento Tradicional Associado, que consiste exatamente no conhecimento tradicional que os indígenas detêm sobre os recursos naturais, mormente no caso Amazônico, no prazo de 60 dias a contar da publicação na Revista Eletrônica da Propriedade Industrial (RPI). Foi a Lei n ${ }^{\circ}$ 13.123/2015 que fez como o INPI desenvolvesse a exigência acima, a qual passou a vigorar a partir de fevereiro de 2018. (MINISTÉRIO DO MEIO AMBIENTE, 2018). 
O certificado de procedência legal é conferido pelo CGEN, tendo como objeto confirmar se o produto ou receita foi obtido em decorrência de acesso a componente do patrimônio genético nacional. Caso positivo, o pleiteante deve provar a origem do componente do patrimônio genético e do conhecimento tradicional, como também o número e a data da autorização de acesso concedida pelo CGEN. A prestação das informações é condição para a continuação do trâmite do pedido de patente. Lembrando que a prestação de informações falsas ao INPI e ao CGEN está sujeita a sanções administrativas e penais, nos termos das respectivas leis.

Como se trata de mudança relativamente recente, ainda não há dados para avaliar se o procedimento tem sido efetivo ou não. O que se pretende é alertar a comunidade jurídica e acadêmica para a relevância do instrumento de proteção, que inclui o respeito aos conhecimentos tradicionais, no processo de reconhecimento de patentes, e de seu efetivo uso, bem como da efetiva fiscalização.

Sugere-se a criação de um sistema global de acesso a recursos genéticos, o qual permitiria a ampliação do alcance da legislação local do país de origem do recurso genético por exploradores estrangeiros. Se colocado em uso efetivo, o certificado tem o condão de combater a biopirataria, garantindo o devido respeito e compensação financeira aos povos indígenas tradicionais, detentores da sabedoria sobre o uso adequado de diversos recursos naturais. Cabe a nós, enquanto brasileiros, usuários dos recursos, aqueles que são fiscalizadores, registradores e afins, intensificar o uso desta ferramenta de proteção tão importante.

\section{REFERÊNCIAS}

AMIN, Mario Miguel. «A Amazônia na geopolítica mundial dos recursos estratégicos do século XXI», Revista Crítica de Ciências Sociais [Online], 107 | 2015, colocado online no dia 04 setembro 2015, criado a 03 julho 2019. URL : http://journals.openedition.org/rccs/5993 ; DOI : $10.4000 /$ rccs.5993

BRASIL. Constituição da República Federativa do Brasil de 1988. Disponível em: . Acesso em: 13 mar. 2019.

FUNAI. O Brasil Indígena. www.funai.govr.br - acesso em 20.10.2015. Lei da Propriedade Industrial, $\mathrm{n}^{\circ} .9 .279$, de 14 de maio de 1996. Disponível em: . Acesso em: 03 jul. 2019.

Lei $n^{\circ}$ 13.123/2015. Lei de Proteção do Patrimônio Genético. Disponível em: . Acesso em: 03 jul. 2019.

Lei número 9.028/95. Dispõe sobre as atribuições da Procuradoria Federal. 
Disponível em: . Acesso em: 03 jul. 2019.

Ministério do Meio Ambiente. Brasil integra sistema de patentes e acesso ao patrimônio genético. Disponível em: < http://www.mma.gov.br/informma/item/3800-brasilintegra-sistema-de-patentes-e-acesso-ao-patrimonio-genetico>. Acesso em: 03 jul. 2019.

Ministério do Meio Ambiente. Conferência das Partes - COP. Disponível em: http://www.mma.gov.br/biodiversidade/conven\%C3\%A7\%C3\%A3o-da-diversidadebiol\%C3\%B3gica/conferencia-das-partes.html. Acesso em 04/07/2019. S_Supremo Tribunal Federal. Pet. 3388/RR. Relator: Ayres Britto. Julgamento: 03/04/2009.

BECKER, Bertha K. Da Preservação à Utilização Consciente da Biodiversidade Amazônica. O Papel da Ciência, Tecnologia e Inovação. In: GARAY, Irene E. G. e BECKER, Bertha K. As Dimensões Humanas da Biodiversidade. O desafio de novas relações sociedade-natureza no século XXI. Petrópolis: Editora Vozes, 2006.

BENSUSAN, Nurit. Biodiversidade, Recursos Genéticos e outros bichos esquisitos. In: O Direito e o desenvolvimento sustentável: curso de direito ambiental. RIOS, Aurélio Virgílio Veiga (org.). São Paulo: Peirópolis, 2005.

CAMPELO, Lilian. Indígena Gamela teve mãos decepadas e joelhos cortados durante massacre. Belém, 2017. Disponível em:

https://www.brasildefato.com.br/2017/05/02/indigena-gamela-teve-maos-decepadas-ejoelhos-cortados-durante-massacre/

FERES, Marcos Viníciu Chein e MOREIRA, João Vitor Freitas. PROTEÇÃO JURÍDICA DA BIODIVERSIDADE AMAZÔNICA: O CASO DO CONHECIMENTO

TRADICIONAL. In Revista Direito Ambiental e Sociedade. Universidade do Sagrado Coração. Bauru, São Paulo, 2014.

FRASER, Nancy e HONNETH, Alex. "From Redistribution to Recognition? Dilemmas of Justice in a 'Post-Socialist' Age’New Left Review I/212, julho-agosto de 1995.

FRITZ, Jean Claude. Las múltiples finalidades del sistema de propriedade intelectualPuesta en perspectiva de un elemento del conflicto entre el derecho internacional de los negocios y el derecho de los pueblos. In: Nuevos colonialismos del capital. Propriedad intelectual, biodiversidad y derechos de los pueblos. RUBIO, David Sánches; ALFARO, Norman J. Solórzano; CID, Isabel V. Lucena (orgs). Barcelona: Icaria Editoria, 2004.

KYMLICKA, Will. The Three Lives of Multiculturalism. In: GUO, Shibao; WONG, Lloyd (Org.). Revisiting Multiculturalism in Canada: theories, policies, and debates. Rotterdam, Netherlands: Sense Publishers, 2015.

HONNETH, Axel. Luta por reconhecimento: a gramática moral dos conflitos sociais. Trad. de Luiz Repa. São Paulo: Ed. 34, 2003;

Organização das Nações Unidas. ONU. Brasil recebe mais de 240 recomendações de direitos humanos na ONU. ONU, 2017. Disponível em: https://nacoesunidas.org/revisao-periodicauniversal-brasil-recebe-mais-de-240-recomendacoes-de-direitos-humanos-na-onu/. Acesso em 
04/07/2019.

PIOVESAN, Flávia. Igualdade, Diferença e direitos humanos: perspectiva global e regional. Rio de Janeiro, Lumen Juris, 2008.

SARMENTO, Daniel. Dignidade da Pessoa Humana - Conteúdo, Trajetórias e Metodologia. Belo Horizonte, Editora Forum, 2016.

SILVEIRA, Adinan Rodrigues da; e ALMEIDA, Andreia Fernandes de. O MULTICULTURALISMO E A DEFESA DE MINORIAS E GRUPOS VULNERÁVEIS NA PERSPECTIVA DO SISTEMA INTERAMERICANO DE PROTEÇÃO DE DIREITOS HUMANOS E NO SISTEMA JURÍDICO BRASILEIRO. Brasil: 2014. Disponível em: http://www.publicadireito.com.br/artigos/?cod=9bbebcea7798629d

STEFANELLO, Alaim Giovani Fortes; DANTAS, Fernando Antônio de Carvalho. A Proteção Jurídica da Sociobiodiversidade Amazônica. In: XVI Congresso Nacional do CONPEDI, Belo Horizonte, 2007.

TAYLOR, Charles. (Org.). Multiculturalismo. Lisboa: Instituto Piaget, 1998.

TÁVORA, Fernando Lagares; NETO, Habib Jorge Fraxe; PÓVOA, Luciano Martins Costa; KÄSSMAYER, Karin; SOUZA, Luís Beltrão Gomes de.; PINHEIRO, Victor Marcel. BASILE, Felipe; CARVALHO, Daniel Melo Nunes de. COMENTÁRIOS À LEI No 13.123, DE 20 DE MAIO DE 2015: Novo Marco Regulatório do Uso da Biodiversidade. Senado Federal, Brasília, 2015.

Periódicos:

COMCIÊNCIA. http://www.comciencia.br/dossies-1-72/reportagens/amazonia/box/gama.htm - acesso em 17.10.2019.

THE INTERCEPT. Gamella tem mãos decepadas. 2019. Disponível em> https://theintercept.com/2019/05/27/gamella-maos-decepadas/ Acesso em 04/07/2019. 